\title{
Propylthiouracil Attenuates Monocrotaline-Induced Pulmonary Arterial Hypertension in Rats
}

\author{
Cheuk-Kwan Sun, MD, PhD; Chun-Man Yuen, MD*; Ying-Hsien Kao, PhD**; \\ Li-Teh Chang, $\mathrm{PhD}^{\dagger}$; Sarah Chua, $\mathrm{MD}^{\dagger \dagger}$; Jiunn-Jye Sheu, MD; \\ Chia-Hung Yen, PhD ${ }^{\dagger}$; Sheung-Fat Ko, MD\$; Hon-Kan Yip, MD
}

\begin{abstract}
Background: Propylthiouracil (PTU) enhances nitric oxide production and inhibits smooth muscle cell proliferation, suggesting a possible role in the prevention of pulmonary arterial hypertension (PAH).

Methods and Results: The 30 male Sprague-Dawley rats were randomized to receive saline injection only (group 1), monocrotaline (MCT) $(70 \mathrm{mg} / \mathrm{kg}$ ) only (group 2) or MCT $+0.1 \%$ PTU in drinking water (group 3) given on day 5 after MCT administration. By day 35, western blot showed lower connexin43 (Cx43) and membranous protein kinase $\mathrm{C}-\varepsilon$ expressions in the right ventricle (RV) of group 2 animals than in the other groups (all $\mathrm{P}<0.05)$. Conversely, $\mathrm{Cx} 43$ expression in the lung was higher in group 2 than in other groups (all $\mathrm{P}<0.02$ ). Additionally, mRNA expressions of matrix metalloproteinase- 9 , tissue necrotic factor- $\alpha$, and caspase- 3 were higher, whereas Bcl-2 and endothelial nitric oxide synthase were lower, in the lungs and RV of group 2 rats than in the other groups (all $\mathrm{P}<0.05)$. Moreover, the numbers of alveolar sacs and lung arterioles were also reduced in group 2 than in other groups (all $\mathrm{P}<0.05$ ), and RV systolic pressure and RV weight were increased in group 2 compared with other groups (all $\mathrm{P}<0.001)$.
\end{abstract}

Conclusions: PTU effectively attenuates complications associated with MCT-induced PAH. $\quad$ (Circ J 2009; 73: 1722-1730)

Key Words: Monocrotaline; Propylthiouracil; Pulmonary arterial hypertension

$\mathbf{P}$ ulmonary arterial hypertension (PAH) is a devastating disease that can drastically limit physical capacity and seriously reduce life expectancy. ${ }^{1-4}$ Pathologic changes of $\mathrm{PAH}$, characterized by vascular smooth muscle cell (VSMC) proliferation and obliteration of small pulmonary arteries, ${ }^{5}$ may ultimately lead to heart failure and death.,3 Despite widespread use of state-ofthe-art medical management against PAH during the past decade, $, 6,7$ the prognosis remains poor. $3,4,8,9$

Although the precise mechanistic basis of PAH is currently unclear, a process involving endothelial dysfunction and VSMC proliferation and migration is essential in the development of all stages of PAH, from initiation, progression, and finally to the evolution of complications. ${ }^{8-10}$ Monocrotaline (MCT), which is known to induce selective pulmonary endothelial injury in rats, ${ }^{8-12}$ causes pulmonary hypertension, interstitial pulmonary fibrosis, and proliferation of muscular intimal cells in pulmonary arterioles and fibroblasts in the alveolar walls at the capillary level. ${ }^{9,11-13}$ Although the pathologic changes in MCT-induced PAH and clinical PAH are not similar, because of differences in pathogenesis, the MCT-induced PAH model has been validated and widely accepted for PAH-related studies because of the consistent induction of selective pulmonary arterio- lar endothelial damage.

In addition to its routine use in patients with hyperthyroidism, because of its thyroid-suppressing function, propylthiouracil (PTU) has also been shown to possess an antioxidant property, ${ }^{14}$ enhance nitric oxide (NO) production, inhibit VSMC proliferation and migration, as well as collagen production. ${ }^{15,16}$ Accordingly, PTU has recently been demonstrated to exhibit an anti-atherosclerotic effect. ${ }^{17,18}$ The aims of this study were, therefore, to determine whether PTU can also effectively attenuate MCT-induced PAH in the rat, in terms of alterations in pulmonary microvasculature and structure, as well as to investigate the underlying mechanisms of biological signaling.

\section{Methods}

\section{Ethics}

All animal experimental procedures were approved by the institutional Animal Care and Use Committee and performed in accordance with the Guide for the Care and Use of Laboratory Animals (NIH publication No. 85-23, National Academy Press, Washington, DC, USA, revised 1996).

(Received February 2, 2009; revised manuscript received April 4, 2009; accepted April 7, 2009; released online July 15, 2009)

Division of General Surgery, *Division of Neurosurgery, $*$ Division of Cardiovascular Surgery, Department of Surgery, **Department of Anesthesiology, ${ }^{\dagger}$ Division of Cardiology, Department of Internal Medicine, ${ }^{\S}$ Department of Radiology, Chang Gung Memorial HospitalKaohsiung Medical Center, Chang Gung University College of Medicine, Kaohsiung, ${ }^{\dagger}$ Basic Science, Nursing Department, Meiho Institute of Technology, Pingtung and $¥$ Department of Life Science, National Pingtung University of Science and Technology, Pingtung; Kaohsiung, Taiwan, ROC

Mailing address: Hon-Kan Yip, MD, Division of Cardiology, Department of Internal Medicine, Chang Gung Memorial Hospital, 123, Ta Pei Road, Niao Sung Hsiang, Kaohsiung Hsien, 83301, Taiwan. E-mail: han.gung@msa.hinet.net

All rights are reserved to the Japanese Circulation Society. For permissions, please e-mail: cj@j-circ.or.jp 


\section{Animal Models of PAH}

On day 0, 20 pathogen-free, adult male Sprague-Dawley (SD) rats, weighing 350-370g (Charles River Technology, BioLASCO Co, Ltd, Taipei, Taiwan) were given a subcutaneous injection of MCT $(70 \mathrm{mg} / \mathrm{kg}$; Sigma, St Louis, MO, USA). On day 5, the MCT-treated animals were assigned to 2 experimental groups: group 2 (MCT alone, $\mathrm{n}=10)$ and group 3 [MCT fed with 0.1\% PTU (Sigma) in drinking water $(n=10)]$. Another group of 10 SD rats (group 1) receiving neither MCT nor PTU treatment served as normal controls. PTU therapy was implemented immediately after the group assignment.

\section{Rationale of the PTU Dosage}

The dosage of the drug was according to previous descriptions; ${ }^{16,17} 0.1 \%$ PTU in water $100 \mathrm{ml}$ is equivalent to $0.27 \mathrm{mg} / 100 \mathrm{ml}$ of drinking water, which was the average daily amount of water consumption for each rat in our study.

\section{Hemodynamic Measurements}

On day 35 after MCT administration, each rat was anesthetized with an intraperitoneal injection of chloral hydrate $(35 \mathrm{mg} / \mathrm{kg})$. After being shaved on the chest, each animal was endotracheally intubated with positive-pressure ventilation $(180 \mathrm{ml} / \mathrm{min})$ with room air using a small animal ventilator (SAR-830/A, CWE Inc, USA). The heart was exposed by left thoracotomy. A sterile 20-gauge, soft plastic-coated needle was inserted into the right ventricle (RV) and femoral artery of each rat to measure the systolic pressure (RVSP) and arterial pressure, respectively. The pressure signals were first transmitted to pressure transducers (UFI, model 1050, Morro Bay, CA, USA) and were then exported to a bridge amplifier (ML866 PowerLab 4/30 Data Acquisition Systems. ADInstruments Pty Ltd, Castle Hill, NSW, Australia) where the signals were amplified and digitized. The data were recorded and later analyzed with the Labchart software (ADInstrument). After hemodynamic measurements, the rats were euthanazed and the hearts and lungs were harvested. For each animal, the RV weight, whole heart weight, and body weight (BW) were recorded and the ratios of RV to whole heart weight and of RV to BW were calculated. The left lung was fixed in $4 \%$ formaldehyde and then embedded in paraffin blocks. The right lung was cut into pieces, frozen in liquid nitrogen and stored at $-80^{\circ} \mathrm{C}$ until future use. These methodologies were based on our recent studies. ${ }^{12,19}$

\section{Western Blot Analysis of Lung Tissue and RV Myocardium}

To evaluate the effect of PTU therapy on the inhibition of overexpression of connexin43 (Cx43), protein aliquots $(30 \mu \mathrm{g})$ of RV and lung were western-blotted for $\mathrm{Cx} 43$ according to manufacturer's instructions. To determine the effect of PTU on protein kinase C (PKC)- $\varepsilon$ expression, protein aliquots $(30 \mu \mathrm{g})$ of $\mathrm{RV}$ were western-blotted for PKC- $\varepsilon$ in the membranous compartment of the RV.

\section{Immunolabeling of Cx43 and Quantitative Image Data Analysis}

Six serial sections of lung and RV tissues (3 longitudinal, 3 transverse) were prepared at $4-\mu \mathrm{m}$ thickness by Cryostat (Leica CM3050S) for $\mathrm{Cx} 43$ immunolabeling according to our recent reports. ${ }^{12,19}$ To co-localize troponin I and Cx43 in the same sample, tissue sections were first incubated with a mixture of polyclonal anti-Cx43 (1:200) plus antiTroponin I $(1: 200)$ for $24 \mathrm{~h}$ at $4^{\circ} \mathrm{C}$, then incubated with anti-mouse FITC (1:200) and anti-rabbit rhodamine (1:200) for $30 \mathrm{~min}$ at room temperature.

Calculation of the integrated area $\left(\mu \mathrm{m}^{2}\right)$ of $\mathrm{Cx} 43$ spots in the tissue sections was achieved using Image Tool 3 (IT3) image analysis software (UTHSCSA; Image Tool for Windows, Version 3.0, University of Texas, Health Science Center, San Antonio, TX, USA). Three selected sections for each animal were quantified. The number of pixels in each Cx43 spot per high-power field (HPF) was first determined, followed by summation of the pixel number obtained from 3 HPFs in each section. The mean pixels number per HPF for each animal was then determined by summation of all pixel numbers divided by 9 . The mean area of $\mathrm{Cx} 43$ per HPF was obtained by adopting a conversion factor of 19.24 $\left(1 \mu \mathrm{m}^{2}\right.$ represented 19.24 pixels) as reported in our recent studies. ${ }^{12,19}$

\section{Real-Time Quantitative Polymerase Chain Reaction (PCR) Analysis}

Real-time PCR was conducted using a LightCycler TaqMan Master (Roche) in a single capillary tube according to the manufacturer's guidelines for individual component concentrations. Forward and reverse primers were each designed in a different exon of the target gene sequence, eliminating the possibility of amplifying genomic DNA. A positive result was determined by identifying the threshold cycle value at which reporter dye emission appeared above background. If a fluorescence signal was not detected within 55 cycles, the sample was considered negative.

\section{Distribution of Alveolar Sacs and Vessels in Lung Parenchyma}

Immunohistochemical staining of $\alpha$-smooth muscle actin (Sigma) was performed to determine the numbers of alveolar sacs and arterioles according to manufacturer's instructions and our recent descriptions. ${ }^{12,19}$ Three lung sections from each rat were chosen and 3 randomly selected HPFs $(\times 100)$ were analyzed in each section. The mean number per HPF for each animal was then determined by summation of all numbers divided by 9 .

\section{Statistical Analysis}

Data are expressed as mean values (mean $\pm \mathrm{SD}$ ). The significance in differences in the data simply between 2 groups was determined by t-test. The means among groups in Table were compared by 1-way ANOVA followed by Tukey multiple comparison procedure. Statistical analysis was performed using SAS statistical software for Windows version 8.2 (SAS institute, Cary, NC, USA). A P-value $<0.05$ was considered statistically significant.

\section{Results}

\section{Hemodynamics, BW, Ratio of RV to Whole Heart Weight}

As shown in Table, the initial and final BW on day 35 after MCT administration did not differ among the 3 groups. There was also no significant difference in whole heart weight between groups 1 and 3 or between groups 2 and 3 . However, the whole heart weight was significantly higher in group 2 than in group 1 . The RV weight was notably higher in group 2 than in groups 1 and 3 , and significantly higher in group 3 than in group 1 . The RVSP on day 35 was substantially higher in group 2 than in groups 1 and 3, and significantly higher in group 3 than in group 1. However, 
Table. Summarized Data of BW, Ratio of RV to Whole HW and Hemodynamics in 3 Groups of Rats

\begin{tabular}{lcccr}
\hline & Group $1^{*}(\mathrm{n}=10)$ & Group 2* $(\mathrm{n}=10)$ & Group 3* $(\mathrm{n}=10)$ & P-value $^{\dagger}$ \\
\hline BW on day 0, $\mathrm{g}$ & $372 \pm 34$ & $364 \pm 46$ & $377 \pm 37$ & 0.475 \\
BW on day 35, $\mathrm{g}$ & $404 \pm 39$ & $379 \pm 54$ & $392 \pm 51$ & 0.157 \\
Total HW, g & $1.41 \pm 0.18^{\mathrm{a}}$ & $1.85 \pm 0.22^{\mathrm{b}}$ & $1.64 \pm 0.30^{\mathrm{a}, \mathrm{b}}$ & 0.035 \\
RV weight, $\mathrm{g}$ & $0.51^{\mathrm{a}} \pm 0.12$ & $1.06^{\mathrm{b}} \pm 0.09$ & $0.84 \mathrm{c} \pm 0.15$ & $<0.001$ \\
RVSP on day 35, mmHg & $28.4^{\mathrm{a}} \pm 4.2$ & $48.8^{\mathrm{b}} \pm 5.8$ & $37.4^{\mathrm{c}} \pm 4.3$ & $<0.001$ \\
FASBP on day 35, mmHg & $126 \pm 25$ & $118 \pm 19$ & $115 \pm 17$ & 0.801 \\
35-day survival (\%) & 100 & 90 & 90 & $>0.5$ \\
\hline
\end{tabular}

*Group 1=normal control; Group 2=MCT treatment only; Group 3=MCT treatment fed with $0.1 \%$ propylthiouracil in drinking water.

†One-way ANOVA. Different letters (a, b, c) indicate significance (at 0.05 level) by Tukey multiple comparison procedure $\left({ }^{\mathrm{a}} \mathrm{vs}^{\mathrm{b}}{ }^{\mathrm{a}}{ }^{\mathrm{a}} \mathrm{Vs}\right.$ ${ }^{\mathrm{c}}$, and ${ }^{\mathrm{b}} \mathrm{vs}^{\mathrm{c}}$, all $\mathrm{P}$ values $\left.<0.05\right)$.

BW, body weight; RV, right ventricle; HW, heart weight; RVSP, right ventricular systolic pressure; FASBP, femoral arterial systolic blood pressure; MCT, monocrotaline.

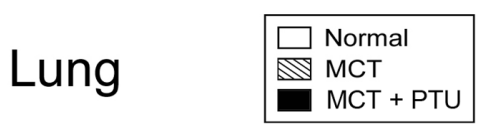

\section{Right Ventricle}

A

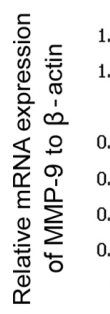
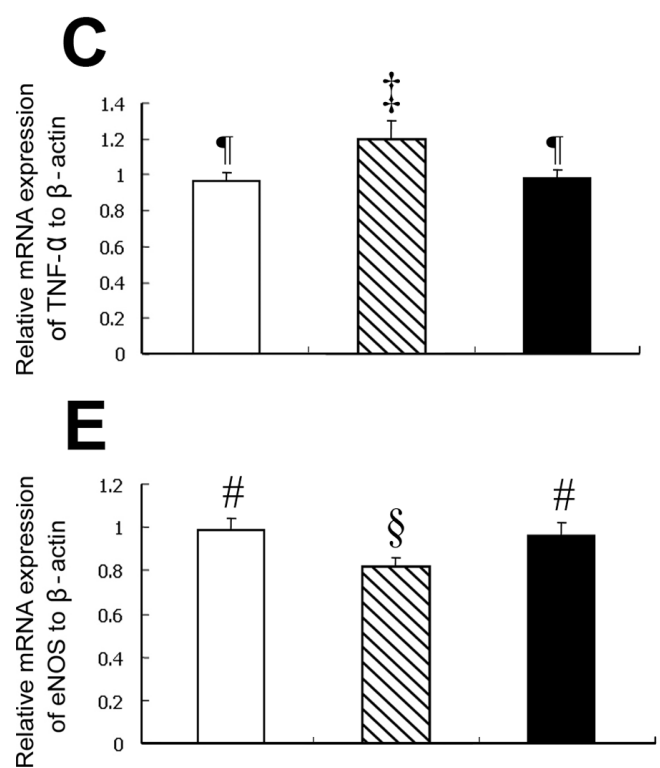

B
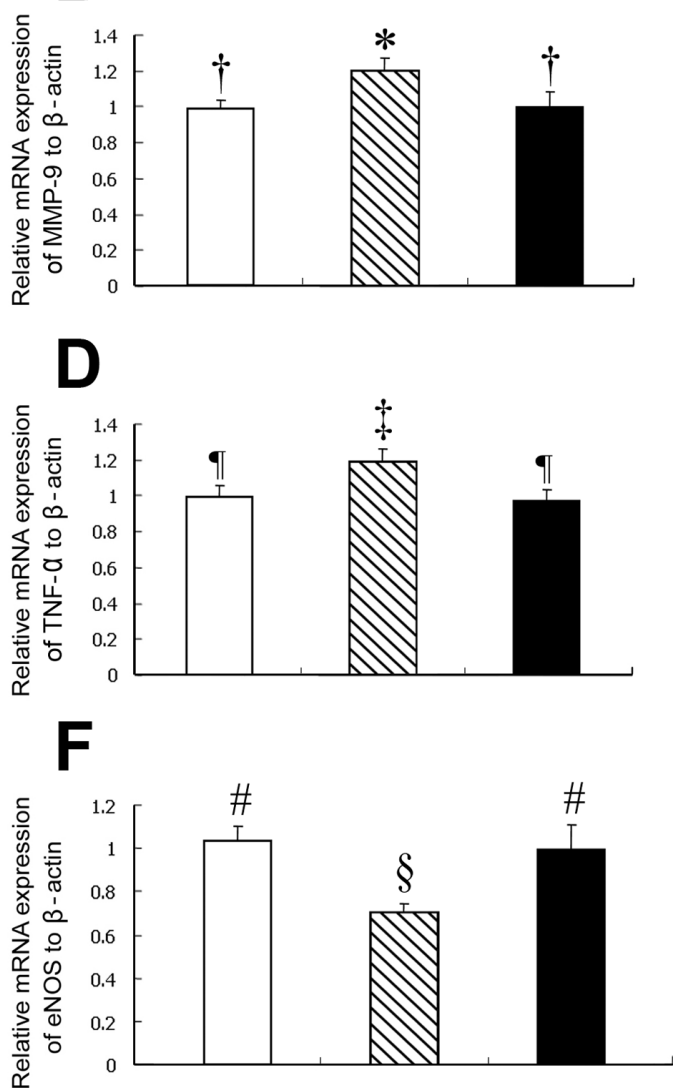

Figure 1. mRNA expression of matrix metalloproteinase (MMP)-9 in lung (A) and right ventricle (RV) (B) of each group of rats on day 35 following monocrotaline (MCT) administration $(\mathrm{n}=6)$. (A) * vs ${ }^{\dagger}, \mathrm{P}<0.045$. (B) * vs ${ }^{\dagger}, \mathrm{P}<0.05$. mRNA expression of tissue necrotic factor (TNF)- $\alpha$ in lung (C) and RV (D) of each group of rats on day 35 following MCT administration $(\mathrm{n}=6)$. (C) $¥$ vs $\mathbb{I}, \mathrm{P}<0.042$. (D) $¥$ vs $\mathbb{I}, \mathrm{P}<0.035$. mRNA expression of endothelial nitric oxide synthase (eNOS) in lung (E) and RV (F) in each group of rats on day 35 following MCT administration (n=6). (E) \& vs \#, $\mathrm{P}<0.045$. (F) ${ }^{\S} \mathrm{vs} \#, \mathrm{P}<0.03$. PTU, propylthiouracil.

the femoral arterial systolic blood pressure and 30-day mortality rate did not differ among the 3 groups.

mRNA Expressions of MMP-9, Tissue Necrotic Factor (TNF)- $\alpha$, and eNOS in the Lung and RV

On day 35 following MCT treatment, the mRNA expres- sions of matrix metalloproteinase (MMP-9) (Figures 1A, B) and TNF- $\alpha$ (Figures 1C,D), 2 indexes of inflammatory status, in both lung tissue and RV were significantly higher in group 2 than in groups 1 and 3 . However, the 2 parameters did not differ between groups 1 and 3 . These findings suggest that PTU had an anti-inflammatory property. Conversely, 
Lung $\quad$ Right Ventricle
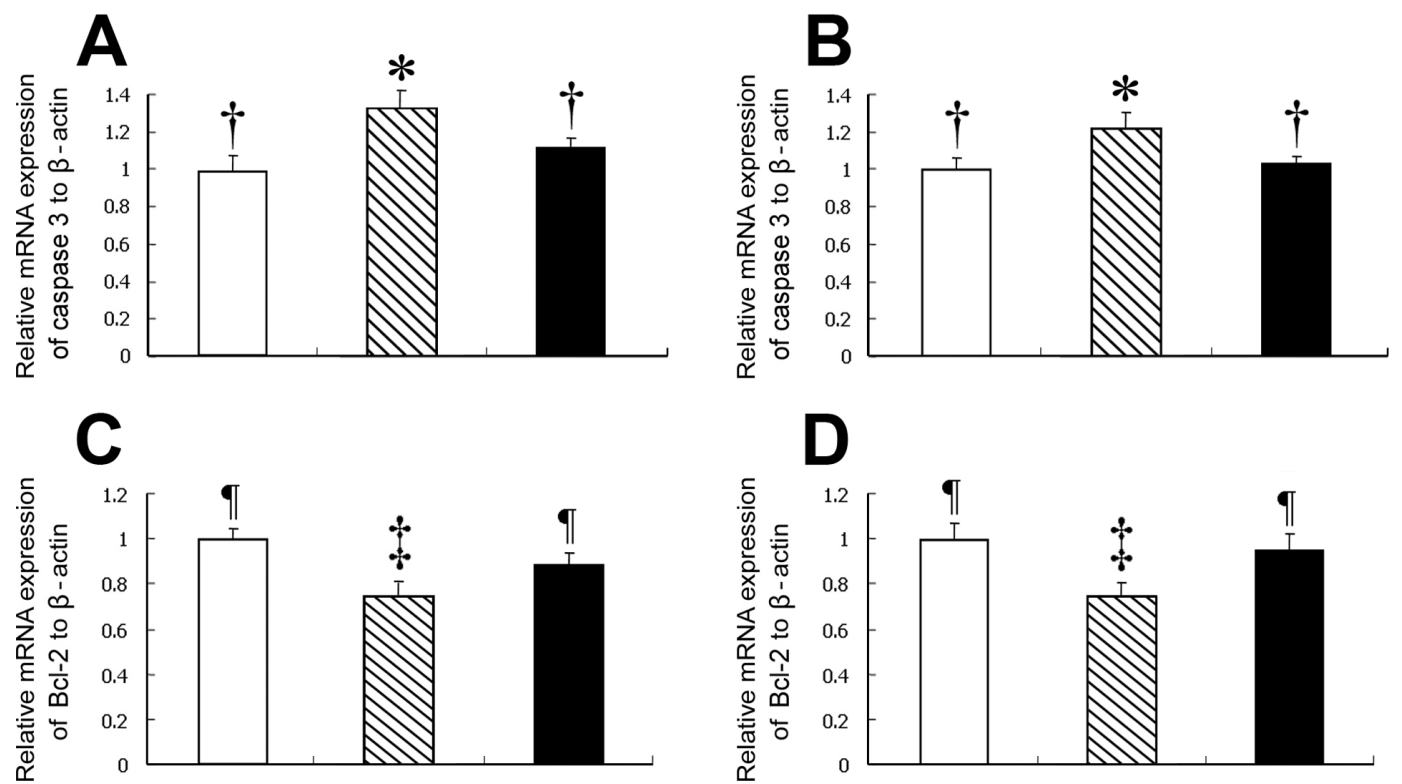

Figure 2. mRNA expression of caspase 3 in lung (A) and RV (B) on day 35 following monocrotaline (MCT) administration $(\mathrm{n}=6)$. $(\mathbf{A}) * v \mathrm{v}^{\dagger}, \mathrm{P}<0.044$. (B) * vs $\dagger, \mathrm{P}<0.05$. mRNA expression of $\mathrm{Bcl}-2$ in lung $(\mathbf{C})$ and $\mathrm{RV}(\mathbf{D})$ in each group of rats on day 35 following MCT administration $(\mathrm{n}=6)$. (C) ₹ vs II, $\mathrm{P}<0.043$. (D) $\ddagger \mathrm{vs}$ II, $\mathrm{P}<0.033$.

the mRNA expression of endothelial NO synthase (eNOS) in both lung tissue and RV was notably lower in group 2 than in groups 1 and 3, whereas it was similar between group 1 and group 3 (Figures 1E,F). These findings indicate significant anti-inflammatory and endothelium-protective effects of PTU therapy.

\section{mRNA Expressions of Caspase 3 and Bcl-2 in the Lung and RV}

On day 35 following MCT treatment, mRNA expression of caspase 3 (Figures $\mathbf{2 A}, \mathbf{B}$ ), an index of apoptosis, in both the lung and RV was significantly higher in group 2 than in groups 1 and 3. However, this mRNA expression was similar between group 1 and group 3. Conversely, Bcl-2 mRNA expression, an index of anti-apoptotic activity, was lower in group 2 than in groups 1 and 3, whereas it was similar between group 1 and group 3 (Figures 2C,D). These findings imply an anti-apoptotic action of PTU in the treatment of MCT-induced PAH in rats.

\section{PKC- $\varepsilon$ Levels in Plasma Membrane and Cytosol of the RV}

Although western blot analysis demonstrated no significant difference in PKC- $\varepsilon$ expression in the membrane compartment (Figure 3A) of the RV myocardium between groups 1 and 3, it was significantly lower in group 2 than in groups 1 and 3 . Additionally, this PKC- $\varepsilon$ expression in the cytosolic compartment (Figure 3B) was notably higher in group 2 than in groups 1 and 3 on day 35 after MCT administration. These findings imply that PTU treatment may trigger a translocation of PKC- $\varepsilon$ from the cytosolic to the membranous domain for RV protection following MCT-induced PAH.
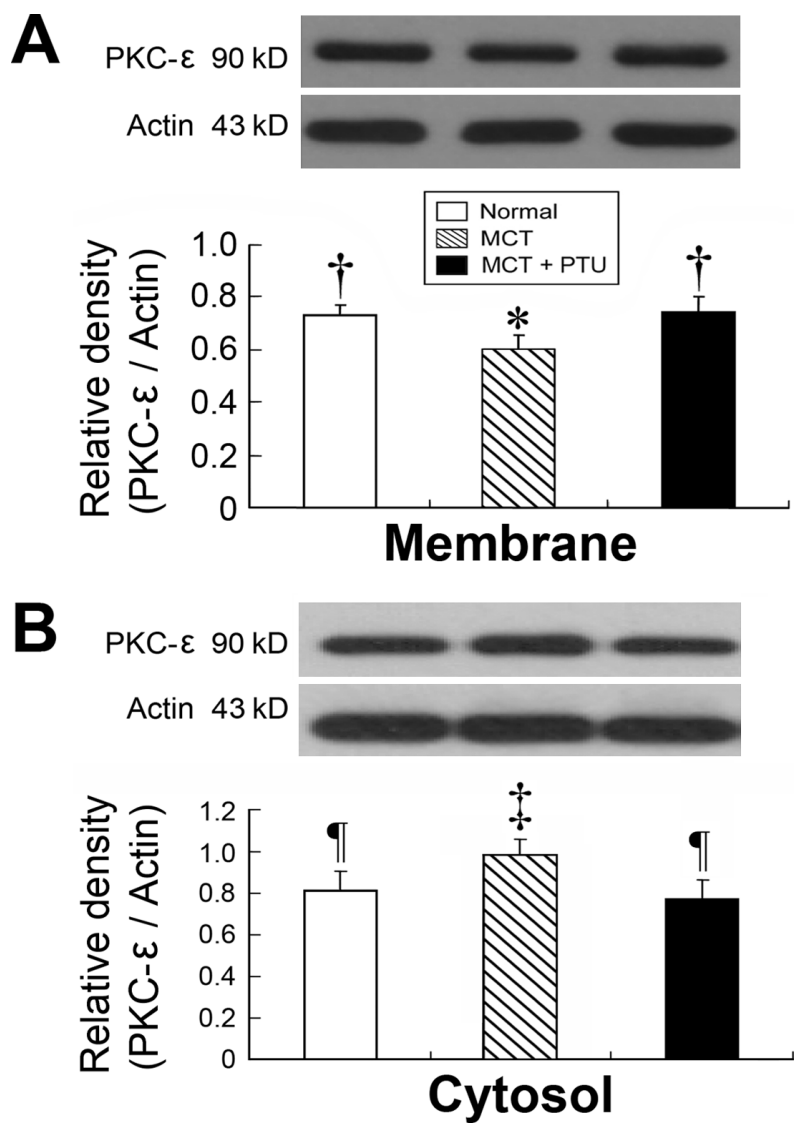

Figure 3. (A) Protein kinase $\mathrm{C}(\mathrm{PKC})-\varepsilon$ expression in the membrane compartment of the right ventricle $(\mathrm{n}=6) .{ }^{*} \mathrm{vs}{ }^{\dagger}, \mathrm{P}<0.04$. (B) $\mathrm{PKC}-\varepsilon$

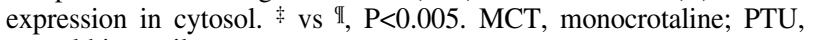
propylthiouracil. 


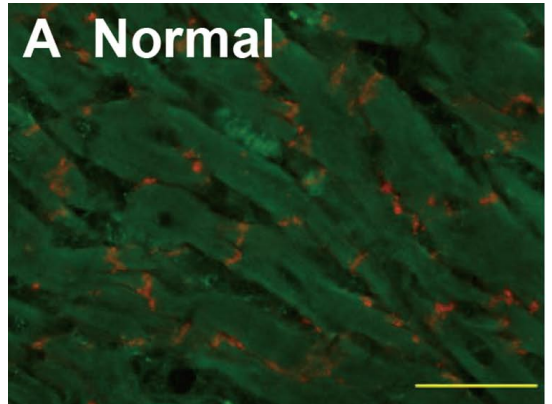

D
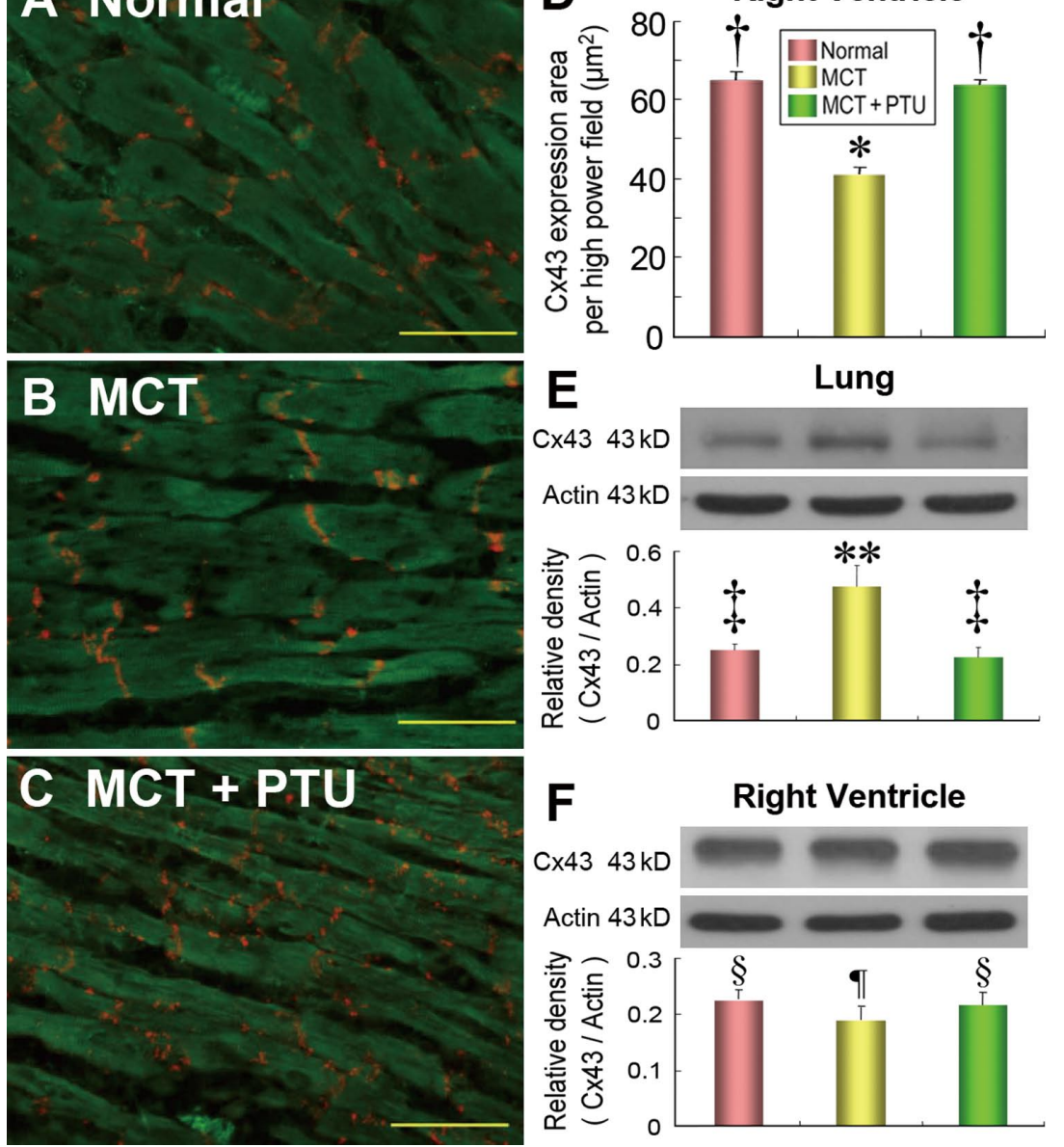

Figure 4. (A-C) Immunofluorescence staining demonstrating notably decreased connexin 43 (Cx43) expression (red spots in the background of green striated myocardium) in monocrotaline (MCT)-treated rats (B) compared with normal controls (A) and MCT-treated rats with propylthiouracil (PTU) treatment $(\mathbf{C})$. Scale bars in right lower corner represent $50 \mu \mathrm{m}$. (D) Integrated area $\left(\mu \mathrm{m}^{2}\right)$ of $\mathrm{Cx} 43 /$ high-power field $(\times 400)$ in each group of rat right ventricle (RV) tissue sample $(n=6)$ on day 35 following MCT administration. * vs ${ }^{\dagger}, \mathrm{P}<0.0001$. (E) Western blot of $\mathrm{Cx} 43$ protein expression in lung. $* *$ vs $\ddagger, \mathrm{P}<0.02$. (F) Western blot of $\mathrm{Cx} 43$ protein expression in RV. II vs $\S, \mathrm{P}<0.05$.
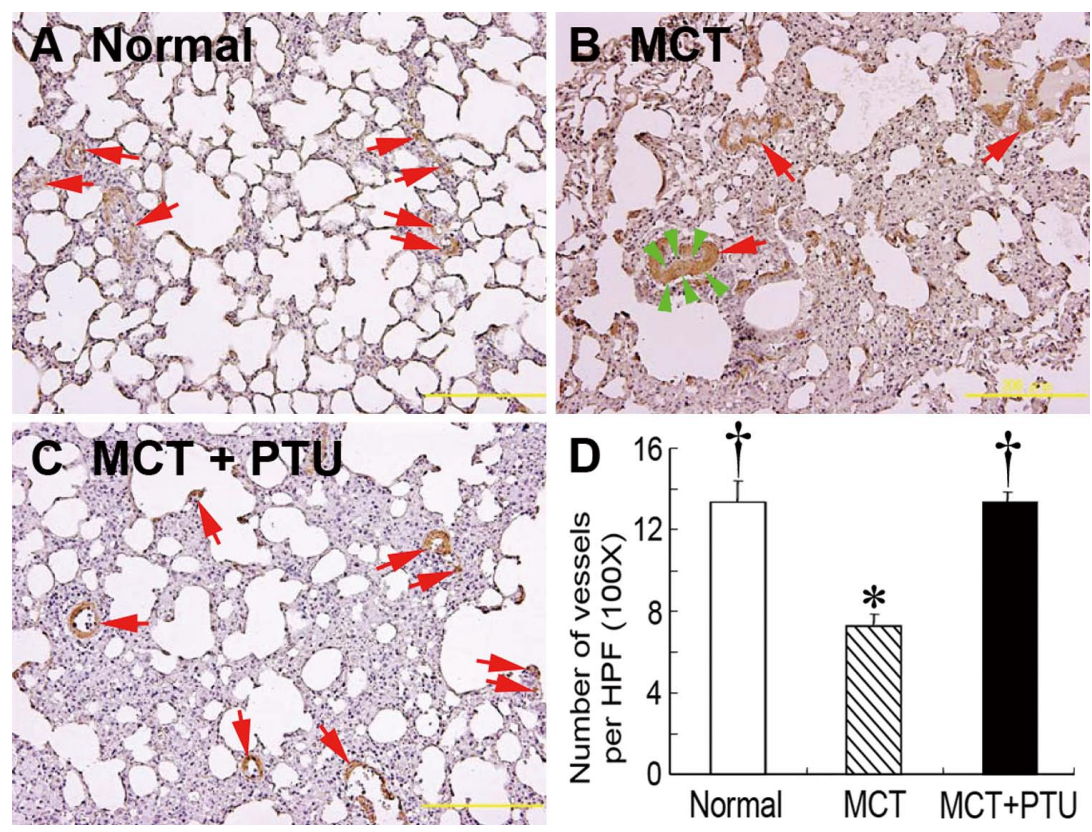

Figure 5. (A-C) Immunohistochemical staining of the lung tissue for number of lung vessels [under HPF $(\times 100)$ ] on day 35 following MCT treatment $(n=6)$. Lower number of small vessels $(<100 \mu \mathrm{m})$ in MCT-treated rats than in the MCT +PTU and normal control groups (red arrows). Additionally, markedly increased thickness of vessel walls (green arrow heads) can be seen in the MCT-treated group than in other groups. The scale bars in the right lower corner represent $200 \mu \mathrm{m}$. (D) * vs ${ }^{\dagger}, \mathrm{P}<0.001$. HPF, high-power field; MCT, monocrotaline; PTU, propylthiouracil.

\section{Cx43 Expression}

Figures 4A-D shows the results of the immunofluorescence imaging study for $\mathrm{Cx} 43$ and quantification of integrated area $\left(\mu \mathrm{m}^{2}\right)$ of clustered Cx 43 spots in each group of $\mathrm{RV}$ tissue samples on day 35 following MCT treatment. The summation area of $\mathrm{Cx} 43$ was significantly lower in group 2 than in groups 1 and 3, whereas no notable difference was noted between groups 1 and 3 (Figure 4D). These findings indicate that PTU therapy was able to preserve $\mathrm{Cx} 43$ expression (ie, an index of gap junction integrity) in the RV 

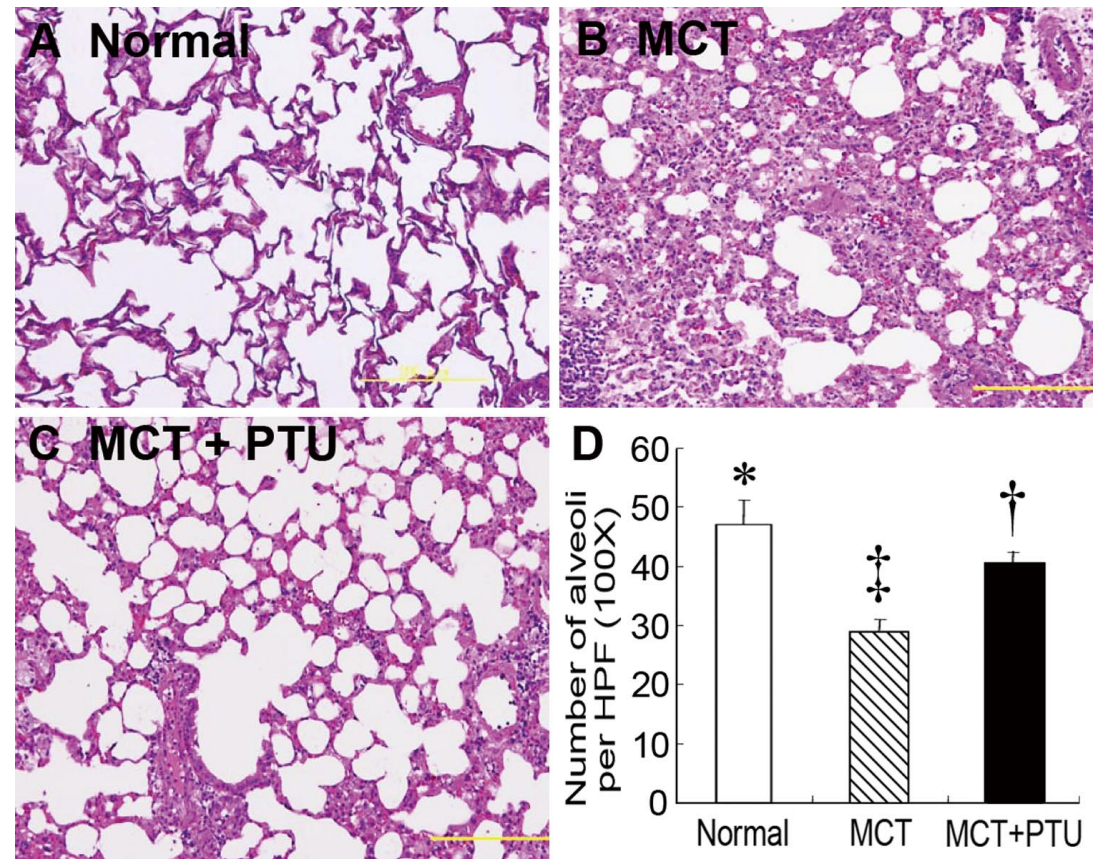

Figure 6. (A-C) Number of alveolar sacs $(\times 100)$ on day 35 following monocrotaline (MCT) treatment $(n=6)$. Remarkably reduced number in the MCT-treated group compared with the other groups $(\mathrm{H} \& \mathrm{E})$. Also note more compact lung parenchyma with thickened septum in the MCT-treated group than in the other groups. Scale bars in the right lower corner represent $200 \mu \mathrm{m}$. (D) $\neq$ vs $\dagger, \mathrm{P}=0.012$; vs $^{*}, \mathrm{P}<0.001$; * vs $\dagger, \mathrm{P}<0.05$. PTU, propylthiouracil; HPF, high-power field.

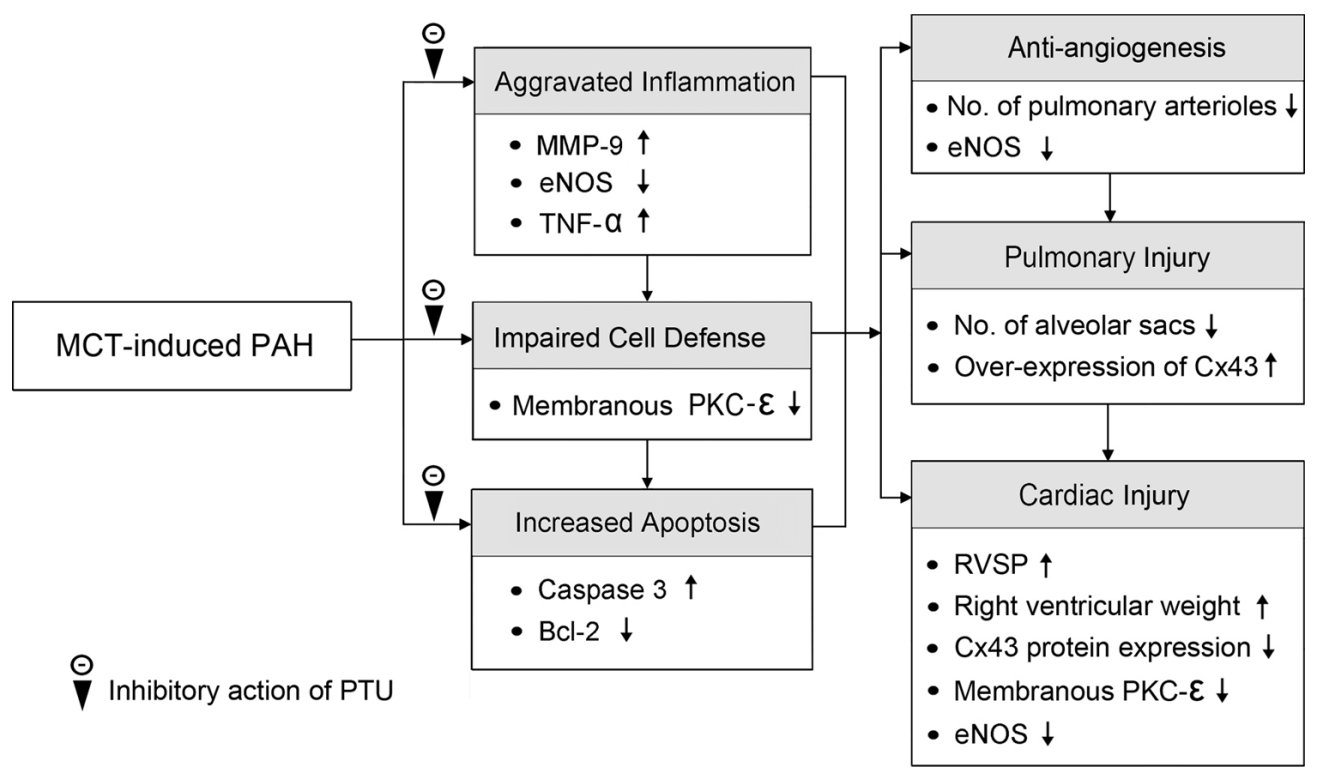

Figure 7. Proposed mechanisms underlying the therapeutic effects of PTU on MCT-induced pulmonary hypertension in rats. MCT, monocrotaline; PAH, pulmonary arterial hypertension; PTU, propylthiouracil; MMP-9, matrix metalloproteinase-9; PKC- $\varepsilon$, protein kinase $\mathrm{C}-\varepsilon ; \mathrm{Cx} 43$, connexin43; RVSP, right ventricular systolic pressure; eNOS, endothelial nitric oxide synthase; TNF- $\alpha$, tissue necrotic factor- $\alpha$.

following MCT-induced lung injury.

Cx43 protein expression in lung tissue (Figure 4E) was significantly higher in group 2 than in groups 1 and 3, whereas there was no notable difference between groups 1 and 3. These findings indicate that MCT administration elicited an early $\mathrm{Cx} 43$ protein overexpression, an index of smooth muscle proliferation in medial layer of vessels and trachea of lung that was attenuated by PTU treatment.

On the other hand, $\mathrm{Cx} 43$ protein expression in the RV (Figure 4F) was notably lower in group 2 than in groups 1 and 3, whereas no significant difference was noted between groups 1 and 3 . These findings suggest that pressure over- load in the RV, an indicator of MCT-induced PAH, markedly suppressed $\mathrm{Cx} 43$ expression in the RV. Besides, PTU therapy preserved $\mathrm{Cx} 43$ protein expression in the $\mathrm{RV}$ on day 35 after MCT treatment.

\section{Quantitative Analysis of Small Arteriolar Density and Number of Alveolar Sacs in Lung Parenchyma}

The number of small vessels $(<100 \mu \mathrm{m})$ in lung parenchyma was substantially reduced in group 2 than in groups 1 and 3 on day 35 following MCT administration (Figure 5). However, the number of small vessels did not differ between groups 1 and 3. Moreover, histopathologic findings revealed 
that arteriolar wall thickness was notably increased in group 2 than in groups 1 and 3, and increased in group 3 compared with group 1 .

Furthermore, microscopically the lung parenchyma was more crowded and the septum more thickened in group 2 than in groups 1 and 3, and in group 3 than in group 1, on day 35 following MCT treatment (Figure 6). In addition, the number of alveolar sacs was substantially lower in group 2 than in groups 1 and 3, and significantly lower in group 3 than in group 1 (Figure 6).

\section{Discussion}

The present study, which investigated the impact of PTU therapy on MCT-induced PAH in the rat, has several striking implications. First, MCT treatment elicited inflammatory responses and apoptosis in the lung and RV, which were effectively attenuated by PTU therapy. Second, PTU upregulated $\mathrm{PKC}-\varepsilon$ expression in the membrane compartment of RV myocardium and suppressed $\mathrm{Cx} 43$ expression in lung parenchyma. Finally, PTU effectively protected the lung against MCT-induced obliteration of microvasculature and destruction of parenchymal architecture. These microcirculatory and ventilatory improvements, in turn, reduce RV pressure overload and hypertrophy, which are key indexes of the severity of PAH. Therefore, PTU may be an attractive therapeutic alternative against $\mathrm{PAH}$-associated pulmonary and cardiac complications.

An important finding in the current study was that not only were the mRNA expressions of TNF- $\alpha$ and MMP-9 markedly elevated in both lung tissue and RV, but the integrity of lung parenchymal architecture was also severely damaged following MCT treatment (Figures 5,6). The findings suggest that MCT-induced PAH inflicts pulmonary and cardiac damage through eliciting inflammatory responses. In addition, a body of evidence has demonstrated an essential role of the involvement of inflammatory mediators in both endothelium and smooth muscle at all stages of atherosclerosis, from initiation, propagation, and the development of complications. ${ }^{20,21}$ Consistently, other studies have further identified that TNF- $\alpha$, an inflammatory cytokine, directly participates in the activation of smooth muscle cell proliferation. ${ }^{22,23}$ Therefore, our proposal of inflammation-based PAH-induced organ damage is supported by those previous studies ${ }^{20-23}$ and may at least partially explain the PAH and RV hypertrophy observed in rats after MCT treatment in this study. Of importance was that PTU therapy significantly suppressed the mRNA expressions of TNF- $\alpha$ and MMP-9 and attenuated the elevation in RV pressure and subsequent myocardial hypertrophy.

Another interesting finding in this study was that MCT treatment significantly enhanced caspase-3 (ie, an index of cellular apoptosis) and suppressed Bcl-2 (ie, an index of anti-cellular apoptosis) mRNA expressions, which could be significantly reversed via PTU treatment. The effect of MCT-mediated PAH on cellular apoptosis in the rat model was identified in our recent studies, ${ }^{12,19}$ the results of which also strengthen the findings of the present study. Although inducing apoptosis of abnormal vascular cells is 1 of the therapeutic aims in treating $\mathrm{PAH},{ }^{24}$ apoptosis of pulmonary artery endothelial cells with loss of small vessels is also implicated as a feature in the pathogenesis of clinical $\mathrm{PAH}^{25}$ and in different animal models. ${ }^{26,27}$ A previous study has shown an increased level of vascular cell apoptosis in a pulmonary hypertension rat model 4 weeks after MCT administration. ${ }^{26}$ Moreover, it has been proposed that early endothelial cell apoptosis of muscular pulmonary arteries is required for the initiation of advanced vascular remodeling. 28 Therefore, apoptosis in the abnormal VSMCs may occur at a later stage after therapeutic intervention against well-established PAH, whereas apoptosis of normal vascular endothelium ${ }^{27}$ and microvascular pericytes ${ }^{25}$ may happen at an early stage of PAH pathogenesis. Because a short-term, MCT-induced PAH animal model was used in this study to mimic early PAH development for an investigation of the therapeutic potential of prompt PTU treatment (ie, 5 days after MCT administration), it is speculated that the observed anti-apoptotic effect of PTU treatment was beneficial in suppressing the initial damage to normal vascular endothelium and hence the resulting vessel loss. This is compatible with the finding of another study that showed an elevated level of vascular cell apoptosis, together with increased smooth muscle cell proliferation, in a MCTinduced PAH rat model. ${ }^{27}$

Moreover, the current study also revealed a remarkable MCT-induced downregulation in PKC- $\varepsilon$ protein expression in RV myocardium, which was notably preserved by PTU therapy. Interestingly, previous studies have shown activation of PKC- $\varepsilon$ during ischemic preconditioning, followed by its translocation to specific subcellular compartments, considered an important mechanism through which PKC- $\varepsilon$ induces downstream signaling cascades and orchestrates protection. ${ }^{29-31}$ Our observation, therefore, is supported by previous studies and may explain the suppression of caspase 3 and preservation of Bcl-2 mRNA expressions in rat RV myocardium following PTU treatment in this study.

One of the most important findings in the present study was the remarkable $\mathrm{Cx} 43$ overexpression in the lung and Cx43 downregulation in the RV following MCT administration. The early expression of $\mathrm{Cx} 43$ has different meanings in the heart and the vasculature. Although the link between RV hypertrophy and downregulation of $\mathrm{Cx} 43$ expression has been identified, ${ }^{32}$ a strong association between $\mathrm{Cx} 43$ overexpression and the smooth muscle cell proliferative response to vascular injury during early development of atherosclerosis has also been reported. ${ }^{33,34}$ In the present study, the significant suppression and preservation of Cx43 expression in the lung and RV, respectively, following PTU treatment in the MCT-treated animals, therefore, signifies a protective role of PTU against PAH in the rat model.

On the other hand, eNOS mRNA expression, an index of $\mathrm{NO}$ production, in both lung tissue and the RV was found to be suppressed by PAH induction in this study. NO is a key vasodilatory molecule regulating vascular tone and which also has antiplatelet, anti-inflammatory, and antioxidant properties. ${ }^{35}$ The lack of eNOS has been demonstrated to be associated with accelerated vascular remodeling with high-flow stress. ${ }^{36}$ The suppressed eNOS expression, therefore, may at least partly explain the remarkable diminution in the number of small vessels and the aggravated arteriolar wall remodeling (Figure 5: thickened arterial wall) in the lung following MCT treatment in the current study. Importantly, the downregulation of eNOS mRNA expression in both the lung and RV was significantly reversed by PTU treatment. Interestingly, PTU has been recently established as possessing properties of increasing NO production, ${ }^{15,16}$ limiting VSMC proliferation, and being anti-atherosclerotic. ${ }^{17,18}$ The findings of the current inves- 
tigation, in addition to reinforcing those of other recent studies, ${ }^{15-18}$ further elucidate the therapeutic potential of PTU in attenuating PAH and RV hypertrophy in the MCTtreated rat model. The proposed mechanisms underlying the potential effect of PTU therapy against MCT-induced PAH in rats have been summarized in Figure 7.

\section{Study Limitations}

First, unlike the MCT-induced inflammation that triggers the proliferation of pulmonary endothelial and VSMCs in the animal PAH model, ${ }^{37}$ it is believed that inflammation is not a main component in the pathogenesis of the clinical situation. However, emerging data begin to arouse the speculation that nonspecific inflammatory processes may be involved during the development of clinical PAH. $38-40$ Second, because only RV pressure and systemic arterial blood pressure were measured in this study without direct measurement of the pulmonary arterial pressure and tricuspid regurgitation pressure gradient, the hemodynamic efficacy of PTU in normalizing PAH cannot be established. Third, thyroid hormone supplementation was not given to the animals in this study to exclude the possible antithyroid effect of PTU on the results of the experiment, as previous studies ${ }^{15,17,18}$ have already demonstrated that the effects of PTU on the inhibition of VSMC proliferation and migration, NO-mediated endothelium-dependent vasodilatation, and reduction in VSMC collagen expression were independent of its antithyroid action. These mechanisms are essentially the same as those investigated in the current study. Furthermore, because the thyroid function test was not performed on the rats receiving PTU, it is unknown to what extent PTU influenced the release of thyroid hormone. We can only speculate that the PTU-treated animals still had a basal level of thyroid hormone, as they showed neither abnormal activities nor an increased rate of mortality. Fourth, although the mechanisms underlying the potential effect of PTU therapy against the complications of MCTinduced PAH in rats have been preliminarily worked out in this study (Figure 7), the precise mechanistic basis of clinical PAH may be more complex. Finally, although shortterm therapy using PTU seems promising and attractive, the long-term effect on PAH in rats has not been clarified.

In conclusion, not only did this experimental study demonstrate a therapeutic application of PTU against PAH-associated pulmonary and cardiac injuries in a MCTinduced PAH rat model through improving the histologic integrity of the pulmonary architecture and microvasculature, it also elucidated the cellular and molecular pathologic mechanisms underlying MCT-induced PAH and the beneficial roles of PTU in these aspects, thereby stimulating further basic and clinical research in this field.

\section{References}

1. Rubin LJ. Primary pulmonary hypertension. N Engl J Med 1997; 336: $111-117$.

2. Branzi A, Manes A, Galie N. Emerging medical therapies for pulmonary arterial hypertension. Prog Cardiovasc dis 2002; 45: 213-224.

3. Runo JR, Loyd JE. Primary pulmonary hypertension. Lancet 2003; 361: $1533-1544$

4. Gaine SP, Rubin L. Primary pulmonary hypertension. Lancet 1998; 352: 719-725.

5. Pietra GG, Edwards WD, Kay JM, Rich S, Kernis J, Schloo B, et al. Histopathology of primary pulmonary hypertension: A qualitative and quantitative study of pulmonary blood vessels from 58 patients in the National Heart, Lung, and Blood Institute, Primary Pulmonary Hypertension Registry. Circulation 1989; 80: 1198-1206.

6. Ikeda D, Tsujino I, Sakaue S, Ohira H, Itoh N, Kamigaki M, et al.
Pilot study of short-term effects of a novel long-acting oral beraprost in patients with pulmonary arterial hypertension. Circ J 2007; 71: $1829-1831$

7. Hiramoto Y, Shioyama W, Kuroda T, Masaki M, Sugiyama S, Okamoto K, et al. Effect of bosentan on plasma endothelin-1 concentration in patients with pulmonary arterial hypertension. Circ J 2007; 71: $367-369$.

8. Archer S, Rich S. Primary pulmonary hypertension: A vascular biology and translational research "Work in progress". Circulation 2000; 102: $2781-2791$.

9. Liu H, Liu ZY, Guan Q. Oral sildenafil prevents and reverses the development of pulmonary hypertension in monocrotaline-treated rats. Interact Cardiovasc Thorac Surg 2007; 6: 608-613.

10. Ogata T, Shibagaki T, Kamma H, Yokose T, Lizima T. Alveolar damage: From epithelial damage and endothelial damage. $J$ Toxicol Pathol 1989; 2: 223-240.

11. Zhao YD, Courtman DW, Deng Y, Kugathasan L, Zhang Q, Stewart DJ. Rescue of monocrotaline-induced pulmonary arterial hypertension using bone marrow-derived endothelial-like progenitor cells: Efficacy of combined cell and eNOS gene therapy in established disease. Circ Res 2005; 96: 442-450.

12. Yip HK, Chang LT, Sun CK, Sheu JJ, Chiang CH, Youssef AA, et al. Autologous transplantation of bone marrow-derived endothelial progenitor cells attenuates monocrotaline-induced pulmonary arterial hypertension in rats. Crit Care Med 2008; 36: 873-880.

13. Ghodsi F, Will JA. Changes in pulmonary structure and function induced by monocrotaline intoxication. Am J Physiol 1981; 240: H149-H155.

14. Hicks M, Wong LS, Day RO. Antioxidant activity of propylthiouracil. Biochem Pharmacol 1992; 43: 439-444.

15. Chen WJ, Ho WJ, Chang GJ, Chen ST, Pang JH, Chou SH, et al. Propylthiouracil, independent of its antithyroid effect, produces endothelium-dependent vasodilatation through induction of nitric oxide bioactivity. Atherosclerosis 2008; 196: 383-390.

16. Grieve DJ, Fletcher S, Pitsillides AA, Botham KM, Elliott J. Effects of oral propylthiouracil treatment on nitric oxide production in rat aorta. Br J Pharmacol 1999; 127: 1-8.

17. Chen WJ, Lin KH, Lai YJ, Yang SH, Pang JHS. Protective effect of propylthiouracil independent of its hypothyroid effect on atherosclerosis in cholesterol-fed rabbits: PTEN induction and inhibition of vascular smooth muscle cell proliferation and migration. Circulation 2004; 110: 1313-1319.

18. Chen WJ, Pang JH, Link KH, Yang SH. Propylthiouracil, independently of its antithyroid effect, decreases VSMC collagen expression. Basic Res Cardiol 2009; 104: 60-68.

19. Chang LT, Sun CK, Sheu JJ, Chiang CH, Youssef AA, Lee FY, et al. Cilostazol therapy attenuates monocrotaline-induced pulmonary arterial hypertension in rat model. Circ $J$ 2008; 72: 825-831.

20. Ross R. Atherosclerosis: An inflammatory disease. $N$ Engl J Med 1999; 340: 115-126.

21. Yip HK, Wu CJ, Chang HW, Yang $\mathrm{CH}$, Yeh $\mathrm{KH}$, Chau S, et al. Levels and values of serum high-sensitivity C-reactive protein within 6 hours after the onset of acute myocardial infarction. Chest 2004; 126: $1417-1422$.

22. Chen YM, Tu CJ, Hung KY, Wu KD, Tsai TJ, Hsieh BS. Inhibition by pentoxifylline of TNF- $\alpha$-stimulated fractalkine production in vascular smooth cells: Evidence for mediation by NF- $\kappa$ B down-regulation. Br J Pharmacol 2003; 138: 950-958.

23. Chen YM, Chiang WC, Lin SL, Wu KD, Tsai TJ, Hsieh BS. Dual regulation of tumor necrosis factor- $\alpha$-induced CCL2/monocyte chemoattractant protein-1 expression in vascular smooth muscle cells by nuclear factor- $\kappa \mathrm{B}$ and activator protein-1: Modulation by type III phosphodiesterase inhibition. J Pharmacol Exp Ther 2004; 309: 978-986.

24. Rabinovitch M. Molecular pathogenesis of pulmonary arterial hypertension. J Clin Invest 2008; 118: 2372-2379.

25. El-Bizri N, Wang L, Merklinger SL, Guignabert C, Desai T, Urashima $\mathrm{T}$, et al. Smooth muscle protein 22alpha-mediated patchy deletion of Bmprla impairs cardiac contractility but protects against pulmonary vascular remodeling. Circ Res 2008; 102: 380-388.

26. Zaiman AL, Podowski M, Medicherla S, Gordy K, Xu F, Zhen L, et al. Role of the TGF-beta/Alk5 signaling pathway in monocrotalineinduced pulmonary hypertension. Am J Respir Crit Care Med 2008; 177: 896-905.

27. Sage E, Mercier O, Van den Eyden F, de Perrot M, Barlier-Mur AM, Dartevelle P, et al. Endothelial cell apoptosis in chronically obstructed and reperfused pulmonary artery. Respir Res 2008; 9: 19.

28. Tuder RM, Yeager ME, Geraci M, Golpon HA, Voelkel NF. Severe pulmonary hypertension after the discovery of the familial primary pulmonary hypertension gene. Eur Respir J 2001; 17: 1065-1069. 
29. Albert CJ, Ford DA. Protein kinase C translocation and PKC-dependent protein phosphorylation during myocardial ischemia. Am J Physiol 1999; 276: H642-H650.

30. Ping P, Zhang J, Qiu Y, Tang XL, Manchikalapudi S, Cao X, et al. Ischemic preconditioning induces selective translocation of protein kinase $\mathrm{C}$ isoforms $\varepsilon$ and $\eta$ in the heart of conscious rabbits without subcellular redistribution of total protein kinase $\mathrm{C}$ activity. Circ Res 1997; 81: 404-414.

31. Ping P, Takano H, Zhang J, Tang XL, Qiu Y, Li RC, et al. Isoformselective activation of protein kinase $\mathrm{C}$ by nitric oxide in the heart of conscious rabbits: A signaling mechanism for both nitric oxideinduced preconditioning. Circ Res 1999; 84: 587-604.

32. Uzzaman M, Honjo H, Takagishi Y, Emdad L, Magee AI, Severs NJ, et al. Remodeling of gap junctional coupling in hypertrophied right ventricles of rats with monocrotaline-induced pulmonary hypertension. Circ Res 2000; 86: 871-878.

33. Blackburn JP, Peter NS, Yeh HI, Rothery S, Green CR, Severs NJ. Upregulation of connexin43 gap junctions during early stages of human coronary atherosclerosis. Arterioscler Thromb Vasc Biol 1995; 15: 1219-1228.

34. Yeh HI, Lupu F, Dupont E, Severs NJ. Upregulation of connexin43 gap junctions between smooth muscle cells after balloon catheter injury in the rat carotid artery. Aterioscler Thromb Vasc Biol 1997; 17: $3174-3184$.

35. Lowenstein CJ, Dinerman JL, Snydel SH. Nitric oxide: A physiological messenger. Ann Intern Med 1994; 120: 227-237.

36. Rudic RD, Shesely EG, Maeda N, Smithies O, Segal SS, Sessa WC Direct evidence for the importance of endothelium-derived nitric oxide vascular remodeling. J Clin Invest 1998; 101: 731-736.

37. Revermann M, Barbosa-Sicard E, Dony E, Schermuly RT, Morisseau $\mathrm{C}$, Geisslinger $\mathrm{G}$, et al. Inhibition of the soluble epoxide hydrolase attenuates monocrotaline-induced pulmonary hypertension in rats. J Hypertens 2009; 27: 322-331.

38. Said SI. The vasoactive intestinal peptide gene is a key modulator of pulmonary vascular remodeling and inflammation. Ann NY Acad Sci 2008; 1144: $148-153$.

39. Steiner MK, Syrkina OL, Kolliputi N, Mark EJ, Hales CA, Waxman $\mathrm{AB}$. Interleukin-6 overexpression induces pulmonary hypertension. Circ Res 2009; 104: 236-244.

40. Aytekin M, Comhair SA, de la Motte C, Bandyopadhyay SK, Farver $\mathrm{CF}$, Hascall VC, et al. High levels of hyaluronan in idiopathic pulmonary arterial hypertension. Am J Physiol Lung Cell Mol Physiol 2008; 295: L789-L799. 